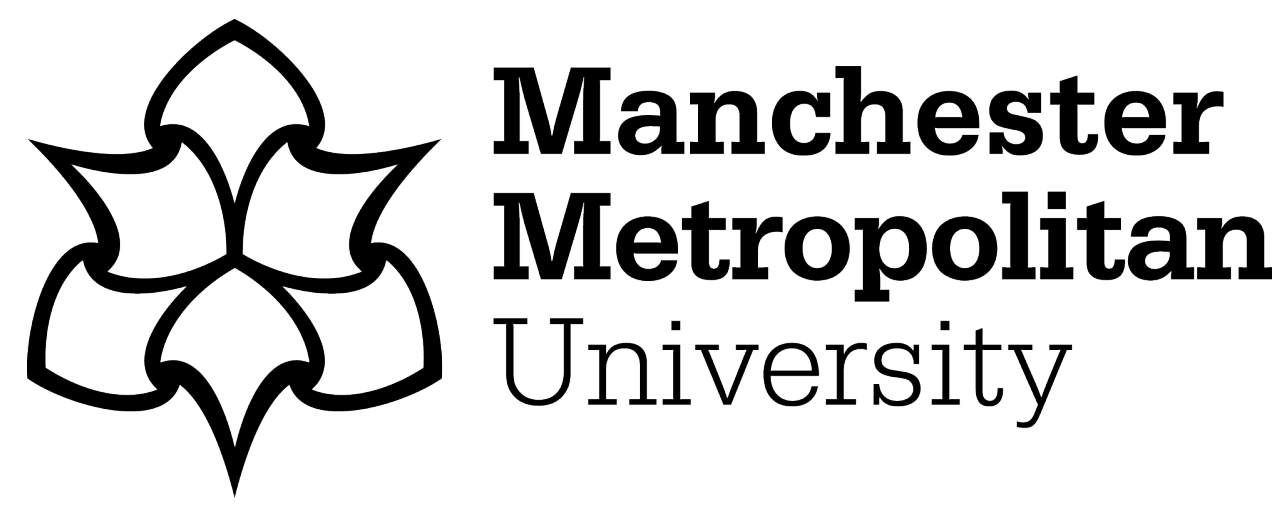

Han, D and tom Dieck, Mandy ORCID logoORCID: https://orcid.org/00000002-8765-8969 (2019) Calling for User-Centric VR Design Research in Hospitality and Tourism. Hospitality and Society, 9 (2). pp. 237-246. ISSN 2042-7913

Downloaded from: https://e-space.mmu.ac.uk/622418/

Version: Accepted Version

Publisher: Intellect

DOI: https://doi.org/10.1386/hosp.9.2.237_7

Please cite the published version 


\title{
Accepted
}

Han, D. \& tom Dieck, M.C. (2019). Calling for User-Centric VR Design Research in Hospitality and Tourism, Hospitality and Society, 9(2).

\section{Calling for User-Centric VR Design Research in Hospitality and Tourism}

\begin{abstract}
VR has enjoyed a steep growth in awareness in society in recent years and is regarded a promising tool for the design and enhancement of experiences. However, as research and use cases in the hospitality context are expanding rapidly, it is crucial to define a clearer research direction that aligns the number of scattered studies across various fields. It is time to overcome the boundaries of the technological dimension and explore methods for purposeful VR design. This research note calls for more user-centric VR studies and developments to define the future direction of VR implementations in the hospitality and tourism industry. To achieve this, the authors recommend the use of design methodology with a focus on the first steps in the design process to clearly identify and understand issues concerning the customer. The customer needs and desires need to be analyzed at the core independent of VR technology. The need to shift the focus from technology to the purpose for the user is identified.
\end{abstract}

Keywords: virtual reality, hospitality, design methodology, user-centric design, research note

\section{Introduction}

Recent developments in virtual and augmented reality technology, such as the launch of ARKit for iOS and ARCore for Android are thriving. VR is expected to become much more affordable in the coming years, reaching a market value of USD 9.1 billion by 2021 and 100 million devices shipped according to CCS Insight and IDC. This means that it will be increasingly important to understand how we can develop VR in a purposeful way to create or add value to the user. In the hospitality context, VR has made a debut in demos such as virtual tours, showrooms and alternative perspectives on certain objects and settings (Qvist et al., 2016). However, once we have passed the 'wow' effect resulting from trialing a new technology, interaction with technology can be considered to be rather underwhelming and does not justify further use 
without adding sufficient value. As an industry that largely deals with intangible products and the increasing emphasis on designing experiences, it is understandable that investments in emerging technologies such as VR have been rather limited, as one negative experience alone is sufficient to potentially lose a large pool of customers. However, as a result, the hospitality industry often seems to be one of the late adopters of new technology, never at the innovation-driving forefront.

Arguably, VR has enjoyed a steeper growth in the last few years compared to AR, due to the exploding number of use cases and demos in various industries such as in education (Parkinson et al., 2017), military (Hodson, 2017) or tourism (tom Dieck et al., 2018), but also due to the more controllable computerized environment to create virtual demos.

Steiner (1992) argued that early VR studies have largely been technology-driven and lacked a focus on processes and adoption. More recent studies, on the contrary, started to focus mainly on user experiences (e.g. tom Dieck et al., 2018). Late studies have repeatedly suggested that VR has the potential to enhance the consumer experience by generating an immersive environment aiming to engage customers with brands and products (Huang et al., 2016). While VR research in the hospitality and tourism industry has been increasing (Griffin et al., 2017; Han et al., 2017; Jung et al., 2018; tom Dieck et al., 2018), the majority of studies focus on the potential virtual enhancement and influence on the visitor experience in line with specific products and contexts such as museums, virtual showrooms or VR enhanced roller coasters in theme parks. We are now at a stage where we comprehend the current technological capabilities of VR as well as have touched upon a number of potential benefits VR could provide for our industry. Future research will determine the direction of VR developments, its purpose in our industry and options of implementation that will shape the use of VR in society. In line with the imminent launch of MagicLeap, by many a longawaited hardware and one of the most-funded companies worth USD 4.5 Billion (Ewalt, 2016), this is a fitting time to think about the impact of such technologies for consumers and businesses. Now, we need to consider how research in these fields should move forward to extract maximum potential of recent advancements and meaningful application in the hospitality industry and greater society. How do we design and implement VR in the hospitality industry to add value to users, encourage repeated use and lasting benefit for consumers and businesses? This paper will review VR studies in hospitality and tourism to date and recommend a design-based approach towards purposeful VR design and development. This article aims to propose a research direction for VR and emerging technologies to foster purposeful design and implementation in the hospitality context to contribute to VR research and development the hospitality industry to support the role of hospitality for the greater society.

\section{Literature Review}




\section{VR in Hospitality and Tourism}

VR is the artificial creation of an environment through the use of head mounted displays (HMD). Due to the capability of affordable devices, the most common senses being used to date are vision and sounds (tom Dieck et al., 2018). So far, research on user implementation and adoption within the hospitality and tourism context has focused on the use of AR (e.g. Han et al., 2017), with only limited research on the potential of VR. In particularly, Rauschnabel and Ro (2016) emphasized that technology implementation research should be conducted early on as it shows the diffusions of new innovations. Therefore, more research and focus on the use of VR in hospitality and tourism is essential in order to ensure a successful adoption by tourists and travelers. One of the first studies on VR adoption was recently conducted by tom Dieck et al. (2018) in the national park context and found that usability factors as well as hedonic, personal and emotional benefits influence tourists' behavioral intentions of VR usage. Nevertheless, their research used a case study design and thus, findings are not generalizable, particularly to a hospitality context. Considering the unique nature of hotels, VR research incorporating issues such as service design or intangibility is essential to fully understand the specific context.

According to a number of researchers (e.g. Jung et al. 2017; Martins et al. 2017) multi-sensory experiences, incorporating for instance vision and sound, are essential for a high level of presence in virtual experiences. This is said to lead to complete absorption, increased enjoyment and positive behavioural intentions towards visiting hotels (Tussyadiah et al., 2016). The so called 'try before you buy' experience, such as the short clips of holiday destinations developed for Samsung Gear VR by Thomas Cook, provides potential hotel or destination visitors with a sense of 'feel' of what a normally intangible product and service entails. Therefore, it aims to offer more security, which is expected to influence behavioral intentions and actual visitations to the hotel and destination (tom Dieck et al., 2018).

In general, there has been a gap in literature when it comes to VR studies in the hospitality and tourism context. While there are a number of studies focusing on user design of AR within the tourism context (e.g. tom Dieck et al., 2016), research within the VR context is very limited with studies so far focusing on the experience design (Gibson \& O'Rawe, 2018) or VR adoption (tom Dieck et al., 2018). Scholars have to review technology focused papers in order to get an understanding how VR applications need to be designed in order to meet the needs and wants of consumers. However, these neglect the specific nature of the tourism industry and therefore, tourism and hospitality-specific research into VR user-centric design should be conducted. In particular, previous studies identified that multi-lingual, easy-to-use and accessible applications should be designed to be accepted by tourists (tom Dieck et al., 2016). 
VR is discussed to be particularly effective as a marketing tool within the hospitality industry as it provides sensory information (Guttentag, 2010). Potential hotel guests are immersed when using HMDs, which makes them isolated from the real world, essentially intensifying the virtual experience (Disztinger et al., 2016). While previous studies all cite potential promising effects due to integrating VR in their product and branding strategy, results remain largely generic and broad linking to outcomes, such as 'enhancing guest and visitor experiences' or 'potential marketing tool for innovativeness'. At the time when these studies were conducted, such conclusions might have been sufficient. However, as the technology develops and consumers as well as businesses get more familiar with the technical capabilities of such technologies, we need to define a substantial purpose for VR design and implementation. This is particularly important as existing studies only look at the potential of using VR to enhance hospitality and tourism experiences with only few case studies actually implementing it in the long run. One of few examples as part of the visitor economy must be theme parks, which were one of the early adopters of VR to gamify attractions such as rollercoasters (Jung et al., 2018).

So far, we have been careful to define the actual return on investment and determine what specifically the technology will provide when talking about 'enhancing experiences' or 'innovative branding'. Naturally, defining these elements requires consideration of the development context. This involves not only the environment of implementation, but needs to recognize the context of the user as well as the context of the developing tool. Subsequently, this implies that the purpose of development for the environment of implementation needs to be identified as well as the end-user or consumer and the suitable tool that is able to satisfy the purpose. Looking at previous studies from the emerging consumer technologies market, there are a number of risks associated with the use of VR for the hospitality industry. These include but are not limited to social acceptance, affordability (tom Dieck et al., 2016), privacy (tom Dieck \& Jung, 2018) and physical risks such as mugging (tom Dieck \& Jung, 2018). Especially today, with ever increasing awareness of data protection, users are more aware and cautioned when it comes to using technology that might record their movements, search behavior and personal preferences. Therefore, businesses and developers need to bear in mind that technology use needs to be transparent in order to provide users with a sense of control, ultimately influencing their decision to accept, use and benefit from VR (Grossmann, 2014). To give an example, in 2016, the Swedish Educational Broadcasting Company (UR) developed a VR experience to create awareness on the effect of bullying in Swedish schools, recording very emotional responses in users who realized the detrimental impact bullying can have on a child's psychology. The possibility to step into someone else's shoes and share that person's experience first-hand is just one of the potential use cases that can be applied to the hospitality industry. This can be beneficial for training purposes to step into the shoes of an executive chef or a hotel manager, or in the recruitment process of potential employees. We believe that such technology needs to be developed with the user-centered design to draw out the full potential of 
emerging technologies and cross the limited perceptions of consumers. Use cases seem to be often bound to immediate and logical implementation cases without exploring alternative options that the same technology can be used for. Therefore, we propose the use of design methodology to recognize and address issues at the core and develop VR solutions that provide value to its users. The objective is to evaluate and identify the best solution from a number of alternatives, which are not technology-driven, but usercentric/problem-driven. VR in this perspective should be recognized as one of the possible solutions, and not necessarily the only solution. Going through this process and identifying a VR application as the best

solution is expected to be much more impactful compared to suggesting VR as the solution based on the current hype of the technology.

\section{Developing user-centric design}

User-centeric design has been identified as crucial perspective to identify, develop and design products and services that are valuable for the end-user, customer or visitor (Sanders \& Dandavate, 1999; Koskinen \& Battarbee, 2003; Sleeswijk Visser et al., 2005). In order to design VR solutions that are valuable from a research perspective and the end-user, we propose going through a step-by-step design process as recognized by professionals and academics (Press \& Cooper, 2017; Smit \& Melissen, 2018). This is useful not only for reducing occurring costs to fix problems afterwards, but to develop solutions that are rooted in the customer's requirements and desires. A number of design processes with different steps has been developed. However, all of them follow very similar lines of thought. Cross (1994) suggests a 7-step approach for design - 1) Clarifying objectives, 2) Establishing functions, 3) Setting requirements, 4) Determining characteristics, 5) Generating alternatives, 6) Evaluating alternatives, and 7) Improving details. The first three steps are focusing on identifying and understanding the problem at hand, while the latter steps are dealing with the development of alternatives and identifying and refining the best possible solution. The use and extent of each design step will be dependent on the product or service that needs to be designed. For VR applications for instance, comparable to other software solutions, it might be more applicable to go through a rapid prototyping process, where a technological prototype or beta version is developed that can be tested and feedback provided by potential users. This type of design is common in software development and is often preferred due to its faster product development and launch potential. For research purposes however, this approach carries a number of issues. Since potential users are testing the working prototype version, it often frames participants in a set of functionalities and content from the start which can limit the participants' perception and context of application. Very often, feedback on such prototypes result in a 'better' version of the current prototype without considering alternative options. For user-centric design, this is not desirable, as developers miss out on potential needs and wishes of users that could have otherwise be exploratively identified. Likewise, in the hospitality context we are dealing with 
experiences as a whole that can be stimulated or enhanced through VR interactions at different points of the overall experience. As a result, rapid prototyping is often not feasible due to the resulting cost and uncontrollable elements that contribute to the overall experience. To address the objective of purposedriven VR development, we suggest that VR research in hospitality and tourism needs a stronger focus on the first steps of the design process, step 1 in particular. Clearly understanding the problem and motivations of users or customers is crucial in order to design research methodologies using VR or VR interactive solutions in a way that are valuable. The Objectives Tree Method, Design Road Mapping or World Café are only a few design tools that can facilitate the identification and understanding of objectives and purposes for developing VR research in this area. While the first two tools are assisting with the organization or objectives and relationships within, the World Café was recognized as a beneficial tool to help participants identify hidden objectives that are not imminent to start with. Previous studies in VR are often based on testing VR prototypes or exploring perceptions and usage intentions. However, having potential users or customers identify objectives related to VR applications or participating in VR research that investigates the perception and behavioral intentions of using VR runs the risk of exploring requirements that are highly perception based and are limited to participants' current understanding of what the technology can do. As a result, it fails to capture issues and desires that are truly important and meaningful for users. The goal in VR research in hospitality and tourism should not be limited to re-inventing applications and VR solutions that are already existing, but to explore non-existing possibilities where VR could take a central role in providing an alternative solution. Creating user-centric purpose-driven VR developments should actively involve users in the design process by not only treating them as research participants, but as co-creators of the design process. The World Café setting can provide a environment where participants can discuss issues and desires that are context-specific before considering alternatives (Step 5 in the design process) that could satisfy a need or solve the issue. While interviews and focus groups are certainly alternative options to explore user requirements and desires, the World Café offers a possibility to engage different stakeholders in a discussion based on a selection of pre-defined topics. Monk (2000) argues that involving all stakeholders that will be affected by the designed product is crucial to ensure effective user-centered design and to clearly understand the context of implementation. This allows for not only sharing different opinions and perspectives, but also helping participants understand the motivation and reasoning for the argument of respective stakeholders as part of the design team.

\section{Discussion}

This research note reflects on VR research in hospitality and tourism to date and suggests a research perspective for future VR research with the aim of purposeful user-centric VR research and development. Taking a design perspective is suggested to avoid thinking driven by technological functionalities as the 
starting point, as this limits the perspective on what one believes a technology should do as a result, shifting away the focus from the problem that actually matters. This suggestion for upcoming research in VR is in line with the tendency of emerging technology studies, where the focus often lies in the exploration of functionalities and the logical use cases thereof.

It is evident that to date VR research in the hospitality industry has taken a rather one-sided approach to implement the technology. Early VR studies in hospitality and tourism have largely focused on the developer side to explore the functionality and capabilities of the technology (Guttentag, 2010; Han et al., 2014). Today, research is increasingly investigating the effect on consumers, exploring the potential benefits this technology can provide by recognizing hedonic values of the end-user (Grossmann, 2014; Tussyadiah et al., 2016; tom Dieck et al., 2018). This seems logical, as we need to understand the functional possibilities and limitations of new technology, before exploring where it can fit in our daily lives. However, we are now at the stage where an increasing amount of research is expected to emerge in the hospitality context on VR use cases and potential applications. Previous studies refer to the potential of what seems to be perceived as promising technology, however, provide limited insights on how exactly the technology is supposed to benefit the consumer or businesses. It seems that the perception of VR in the industry is largely related to the technological functions it provides, limiting the scope of imagination to what has been developed and can be seen. There seems to be a misalignment between what is really valued and what VR can provide as technology. Only after clearly understanding the problem or desire, can we start looking for solutions and evaluating alternatives. As we move forward, we suggest that technology research such as VR needs to be conducted from the raw identification of purpose and benefit for the user as well as the implemented context. This includes the user's immediate environment and peers in the surrounding area, but also the supplier of the experience, the local community as well as wider society. This implies that VR, AR or any other emerging technology cannot be the starting point of problem solving and research. Instead, we need to step back and reevaluate the challenges and opportunities that people are facing in the hospitality context and in society as a whole. VR provides a tremendous potential in the hospitality context using the sense of 'presence' provided with the user's VR perspective. This can be used to shadow a day in the life of a hotel manager or executive chef and experience what the industry is like first-hand. The actual issue to be solved however might be rooted in HR to select candidates or for training purposes providing feedback on processes and reactive evaluations with the aim of tackling staff turnover, a common issue among hospitality businesses globally.

To drive purposeful design, we therefore propose to put the user and the existing context in the center of development. Content as well as interaction driven by VR requires to be developed to serve a specific purpose, and should not be driven by technological possibilities for the sake of technology implementation 
and 'innovative' branding. We suggest making a stronger link between perspectives, such as the consumer and developer in order to assure specific demands to be met with the right technological solution, through tools such as Quality Function Deployment (QFD). QFD is a tool within the framework of Total Quality Management (TQM) that suggest a customer-centered approach to product design, where the voice of the customer is collected and implemented in the design stage in an attempt to design a product that is based on customer requirements. It was argued that this does not only result in a higher perceived quality product, but also reduces cost due to limited corrections that will be necessary after the product is completed. This mindset will imply that for some improvements, VR might result in not to be the suitable technology, and alternative solutions have to be considered. Accepting VR as only one of many solutions can shift the perspective on product design. Focusing on the core problem instead of a predetermined (technological) solution can safeguard from many underwhelming consumer experiences, applications limited to gimmicks and vast amounts of resources wasted.

\section{Conclusion}

Technology such as VR has the potential to revolutionize the way we experience and interact with products in the hospitality industry and wider society. However, current advancements in VR research in the hospitality context take a rather limited perspective on purpose-driven design, leading to believe that methods of VR implementation in the hospitality and tourism context have not been fully grasped yet. At the current stage of VR's technological capabilities, it is essential to investigate and introduce VR implementations meaningfully in hospitality to extract its full potential to innovate our industry. To allow for VR designs that are able to trigger emotional responses and generate meaningful experiences, this research note takes a clear position for the future direction of this research area. We suggest that the design of forthcoming studies needs to be purpose-driven to be designed with a clear goal in mind by embedding various stakeholder perspectives such as of the end user as well as research commissioner. Through purpose-driven VR research in the hospitality and tourism context, the authors see an opportunity for our industry to make a greater contribution to the development of consumer experiences and greater society. As the role of generating memorable experiences as a consumer product is increasingly gaining importance, it is our hope that this research note provides a starting point for the future direction of VR research in hospitality and tourism when forming research studies in this area and driving VR implementation for the growth of society. 


\section{References}

Brown, J., 2010. The world café: Shaping our futures through conversations that matter. ReadHowYouWant. com.

Cross, N., 1994. Engineering design methods. Strategies for Product Design, ed. John Wiley and sons.

Disztinger, P., Schlögl, S. and Groth, A., 2017. Technology acceptance of virtual reality for travel planning. In: R. Schegg and B. Stangl eds. Information and Communication Technologies in Tourism 2017 (pp. 255-268). Springer, Cham.

Ewalt, D. M., 2016 "Inside Magic Leap, The Secretive \$4.5 Billion Startup Changing Computing Forever".

Forbes. https://www.forbes.com/sites/davidewalt/2016/11/02/inside-magic-leap-the-secretive-4-5billion-startup-changing-computing-forever/\#5fefd724223d

Gibson, A. and O'Rawe, M. (2018). Virtual reality as a travel promotional tool: Insights from a consumer travel fair. In Augmented reality and Virtual Reality (pp.93-108). Springer, Cham.

Griffin, T., Giberson, J., Lee, S.H.M., Guttentag, D., Kandaurova, M., Sergueeva, K. and Dimanche, F., 2017. Virtual reality and implications for destination marketing.

Grossmann, E., 2014. How Transparency Improves Mobile App Production [online]. https://possiblemobile.com/2014/03/transparency-improves-mobile-app-production/

Guttentag, D.A., 2010. Virtual reality: Applications and implications for tourism. Tourism Management, 31(5), pp.637-651.

Han, D.I., tom Dieck, M.C. and Jung, T., 2018. User experience model for augmented reality applications in urban heritage tourism. Journal of Heritage Tourism, 13(1), pp.46-61.

Huang, Y.C., Backman, K.F., Backman, S.J. and Chang, L.L., 2016. Exploring the implications of virtual reality technology in tourism marketing: An integrated research framework. International Journal of Tourism Research, 18(2), pp.116-128.

Martins, J., Gonçalves, R., Branco, F., Barbosa, L., Melo, M. and Bessa, M., 2017. A multisensory virtual experience model for thematic tourism: A Port wine tourism application proposal. Journal of destination marketing \& management, 6(2), pp.103-109.

Metz, R., 2018. Facebook's head of social VR admits there isn't much to do in its social VR app. MIT Technology Review. https://www.technologyreview.com/s/611041/facebooks-head-of-social-vradmits-there-isnt-much-to-do-in-its-social-vr-app/

Monk, A. (2000). User-centred design. In Home informatics and telematics (pp. 181-190). Springer, Boston, MA.

Jung, T., tom Dieck, M.C., Moorhouse, N. and tom Dieck, D., 2017, January. Tourists' experience of Virtual Reality applications. In Consumer Electronics (ICCE), 2017 IEEE International Conference on (pp. 208-210). IEEE.

Jung, T., tom Dieck, M.C., Rauschnabel, P., Ascenção, M., Tuominen, P. and Moilanen, T., 2018. Functional, Hedonic or Social? Exploring Antecedents and Consequences of Virtual Reality Rollercoaster Usage. In Augmented Reality and Virtual Reality (pp. 247-258). Springer, Cham.

Koskinen, I. and Battarbee, K., 2003. Introduction to user experience and empathic design. In: I. Koskinen, K. Battarbee, and T. Mattelmäki, eds. Empathic design, user experience in product design. Helsinki: IT Press, pp.37-50. 
Press, M. and Cooper, R., 2017. The design experience: the role of design and designers in the twenty-first century. Routledge.

Qvist, P., Trygg, N.B., Luimula, M., Peltola, A., Suominen, T., Heikkinen, V., Tuominen, P. and Tuusvuori, O., 2016, October. Medieval gastro box-Utilizing VR technologies in immersive tourism experiences. In Cognitive Infocommunications (CogInfoCom), 2016 7th IEEE International Conference on (pp. 000077-000078). IEEE.

Rauschnabel, P.A. and Ro, Y.K., 2016. Augmented reality smart glasses: An investigation of technology acceptance drivers. International Journal of Technology Marketing, 11(2), pp.123-148.

Rubin, P., 2018. With venues, oculus and facebook push social VR into new territory. Wired. https://www.wired.com/story/oculus-venues/

Sanders, E.B.N. and Dandavate, U., 1999. Design for experiencing: new tools. In: C.J. Overbeeke and P. Hekkert, eds. Proceedings of the first international conference on design and emotion, 3-5 November 1999, The Netherlands: Delft University of Technology, Delft, pp.87-92.

Schieffer, A., Isaacs, D. and Gyllenpalm, B., 2004. The world café: part one. World, 18(8), pp.1-9.

Smit, B. and Melissen, F., 2018. Sustainable Customer Experience Design: Co-creating Experiences in Events, Tourism and Hospitality. Routledge.

Steuer, J. (1992). Defining virtual reality: Dimensions determining telepresence. Journal of communication, 42(4), 73-93.

Visser, F. S., Stappers, P. J., Van der Lugt, R., \& Sanders, E. B. (2005). Contextmapping: experiences from practice. CoDesign, 1(2), 119-149.

tom Dieck, M.C. and Jung, T., 2018. A theoretical model of mobile augmented reality acceptance in urban heritage tourism. Current Issues in Tourism, 21(2), pp.154-174.

tom Dieck, M.C., Jung, T. and Han, D.I., 2016. Mapping requirements for the wearable smart glasses augmented reality museum application. Journal of Hospitality and Tourism Technology, 7(3), pp.230-253.

tom Dieck, D., tom Dieck, M.C., Jung, T. and Moorhouse, N., 2018. Tourists' virtual reality adoption: an exploratory study from Lake District National Park. Leisure Studies, pp.1-13.

Tussyadiah, I., Wang, D. and Jia, C.H., 2016. Exploring the persuasive power of virtual reality imagery for destination marketing. 